\title{
Clinical Reasoning: Headaches and double vision in a 68-year-old woman
}

Lorenzo Rinaldo, MD, PhD, Catherine E. Arnold Fiebelkorn, MD, John J. Chen, MD, PhD, and Giuseppe Lanzino, MD

Neurology ${ }^{\circledR}$ 2018;91:e785-e789. doi:10.1212/WNL.0000000000006046

\author{
Correspondence \\ Dr. Lanzino \\ Lanzino.Giuseppe@ \\ mayo.edu
}

\section{Section 1}

A 68-year-old woman presented with increased frequency of headaches accompanied by double vision. The patient had a history of migraines, which she typically experienced on a monthly basis. In the month prior to presentation, the frequency of her headaches gradually increased to daily and had become more common at night and upon waking from sleep. She also noted the recent development of double vision with vertical and horizontal gaze. Finally, she reported associated nausea, light, and noise sensitivity, which was typical of her usual migraines, as well as generalized fatigue and a feeling of being "off-kilter." Her medical history was significant for right-sided breast cancer treated with radical mastectomy, since then in remission.

On physical examination, the patient was afebrile with normal vital signs. Her mental status and language function were normal. Visual fields were intact and pupils were reactive to light without anisocoria. There was no evidence of papilledema. Extraocular movement examination demonstrated a mild elevation and adduction deficit consistent with a partial pupil sparing right-sided oculomotor nerve palsy. There was no ptosis. Cranial nerve examination was otherwise unremarkable. She had a normal motor and sensory examination, and symmetrically reduced deep tendon reflexes throughout. Her gait examination was significant for astasiaabasia.

\section{Questions for consideration:}

1. Is intracranial imaging warranted as part of the initial workup for this case?

2. Which elements of the patient's presentation argue for or against the need for imaging?

GO TO SECTION 2

From the Departments of Neurosurgery (L.R., G.L.), Neurology (C.E.A.F., J.J.C.), Ophthalmology (J.J.C.), and Neurointerventional Radiology (G.L.), Mayo Clinic, Rochester, MN. Go to Neurology.org/N for full disclosures. Funding information and disclosures deemed relevant by the authors, if any, are provided at the end of the article. 


\section{Section 2}

The change in frequency in the patient's headache, predilection for nocturnal and early-morning onset, history of malignancy, and abnormal neurologic examination suggested the presence of a mass lesion or increased intracranial pressure (ICP) and appropriately prompted imaging in this patient. ${ }^{1}$ In addition, the presence of a partial third nerve palsy, even if pupil sparing, requires imaging to evaluate for the presence of a posterior communicating artery aneurysm. ${ }^{2}$ Apart from an aneurysm, though the list of intracranial lesions that could potentially cause the patient's presentation is extensive, more likely etiologies included an extra-axial lesion along the medial sphenoid wing, anterior clinoid, or within the cavernous sinus. Microvascular third nerve palsy, due to undiagnosed hypertension or diabetes mellitus, was also considered as it is the most common cause of oculomotor nerve palsy. ${ }^{2}$ Head CT and follow-up MRI demonstrated a right-sided, homogenously enhancing extraaxial frontotemporal mass with minimal associated right-to-left midline shift. A CSF cleft was visible around the margins of the lesion and there was no evidence of nearby sulcal effacement (figure, A). The patient was initiated on oral dexamethasone after discovery of the mass with no effect on the intensity of her headaches.

Also noted on the MRI was a vascular abnormality within the interhemispheric fissure close to the floor of the anterior cranial fossa (figure, B). Follow-up cerebral angiography demonstrated an arteriovenous malformation (AVM) fed by the frontopolar branch of the anterior cerebral artery in the right gyrus rectus, with venous drainage through a torturous interhemispheric vein leading to the anterior superior sagittal sinus (SSS; figure, C). Multiple flow-related aneurysms were present on arterial pedicles feeding the malformation (figure, $\mathrm{C}$ and $\mathrm{D}$ ). In addition, diffuse narrowing of multiple branches of the bilateral external carotid arteries, including both superficial temporal arteries (STA), was noted (figure, E).

\section{Questions for consideration}

1. What laboratory tests are warranted in this patient?

2. Which of the patient's multiple abnormalities is most likely responsible for her headaches?

3. Which of the patient's multiple abnormalities is most likely responsible for her double vision?

GO TO SECTION 3 
Figure Imaging and biopsy findings
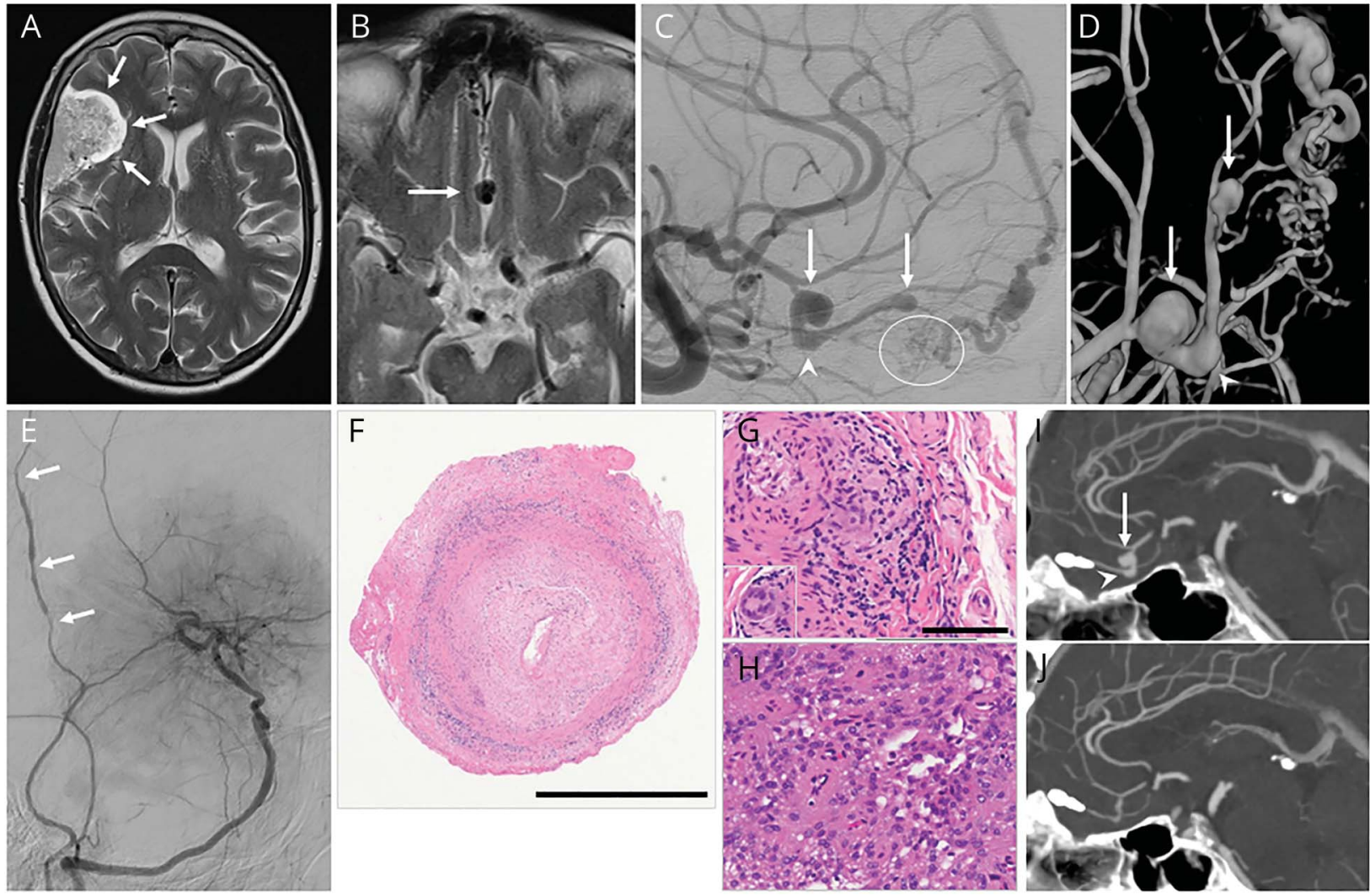

(A) Axial T2-weighted images demonstrate an extra-axial right frontal tumor with subarachnoid CSF signal medial to the lesion (white arrows), and no evidence of nearby sulcal effacement. (B) A prominent flow void (arrow) is noted within the interhemispheric fissure, suggestive of a small aneurysm. (C) Digital subtraction angiography demonstrates an arteriovenous malformation (AVM) with the nidus (circle) located in the right gyrus rectus and drainage via a tortuous interhemispheric vein into the superior sagittal sinus. Also noted are 2 flow-related aneurysms (arrows) and dysplasia of the main feeding artery (arrowhead). (D) The aneurysms (arrows) and vessel dysplasia (arrowhead) were again seen on 3D reconstructions. (E) Also visualized on angiography are irregularities with "beading" of the distal superficial temporal artery (STA; arrows), along with the tumor blush of the right-sided frontotemporal meningioma. Pathologic evaluation of the STA demonstrates concentric intimal hyperplasia (F) with evidence of inflammatory infiltrate (G); a multinucleated giant cell is visualized in the inset of $(\mathrm{G})$. The scale bars in panels $\mathrm{F}$ and $\mathrm{G}$ are 1 millimeter and 100 micrometers in length, respectively. Pathologic image of right frontotemporal mass taken at 200x magnification is consistent with a WHO grade 1 meningothelial meningioma (H). Comparison of CT angiography performed immediately postoperatively (I) and at 3 months follow-up (J) demonstrates involution of previously seen proximal feeding pedicle aneurysm (arrow) and normalization of vessel dysplasia (arrowhead). No residual AVM was noted on either scan. 


\section{Section 3}

On further questioning, the patient reported jaw pain, but denied jaw claudication or scalp pain. Erythrocyte sedimentation rate and C-reactive protein were elevated at $57 \mathrm{~mm} / \mathrm{h}$ (reference range $[\mathrm{RR}] 0-29 \mathrm{~mm} / \mathrm{h}$ ) and $11.6 \mathrm{mg} / \mathrm{L}(\mathrm{RR} \leq 8.0$ $\mathrm{mg} / \mathrm{L}$ ), respectively. A diagnosis of temporal arteritis was suspected, and thus a biopsy of the right STA concomitantly with a bilateral frontal craniotomy for removal of the AVM and clipping of the feeding pedicle aneurysms was performed. At the time of surgery, the right STA was noted to be diffusely thickened and abnormal, and pathologic examination confirmed the diagnosis of giant cell arteritis (figure, F and G). Following a bifrontal craniotomy, the nidus of the AVM was located in the right gyrus rectus. After coagulation and division of all arterial feeders, the draining vein was ligated and the nidus was removed. The more distal feeding pedicle aneurysm was clipped without incident, while treatment of the more proximal aneurysm was eschewed given the deep location and high likelihood of spontaneous regression after AVM resection. ${ }^{3}$ The patient's right-sided extra-axial lesion was thought to be an incidental benign meningioma, which was confirmed by biopsy at the time of AVM resection (figure, $\mathrm{H}$ ). Postoperatively, the patient was continued on high-dose steroids. The intensity of her headaches improved almost immediately after surgery and she had an uneventful recovery. On follow-up examination, her headaches and double vision had resolved and she reported "feeling like her normal self again." Imaging demonstrated involution of the untreated feeding pedicle aneurysm (figure, I and J), complete exclusion of the AVM, and tumor stability.

\section{Discussion}

In the practice of medicine, there is an appropriate predisposition to explain multiple signs and symptoms with a single pathologic process. As this case demonstrates, however, patients can have multiple rare pathologies contributing differentially to one, complex clinical presentation. Although uncommon, this possibility is important to consider when the clinical presentation does not fit nicely into a unifying diagnosis. Further, it is important to avoid being blinded from alternative explanations by impressive signs and symptoms or findings of investigative studies.

In this case, the right-sided meningioma was the most notable initial radiographic finding, and due to its substantial size was reasonably suspected of causing the patient's headaches through an increase in ICP. However, the absence of mass effect associated with the lesion made this assertion somewhat dubious (figure, B). Moreover, the patient's diplopia, secondary to a right oculomotor nerve palsy, was not explained by the mass. The association of increased ICP with abducens nerve palsies is well-established, but in the absence of direct mass effect elevated ICP rarely, if ever, causes oculomotor nerve dysfunction. ${ }^{3,4}$ Subsequent vascular imaging revealed 2 additional pathologies: irregularities in the caliber of bilateral external carotid artery branches consistent with temporal arteritis and an AVM located in the right gyrus rectus draining into the SSS. Temporal arteritis can produce both headaches and oculomotor nerve palsies, ${ }^{5}$ and thus was briefly considered to represent a unifying diagnosis. However, the patient described headaches that were holocephalic (rather than lateralized) and worse upon awakening, which was more consistent with increased ICP as the underlying etiology. This was supported by the lack of headache improvement and actual worsening despite high-dose steroid therapy before surgery. High-flow AVMs, which likely describes the patient's AVM given the presence of multiple feeding pedicle aneurysms, produce arterialization of draining veins and subsequent venous hypertension. In addition to headaches consequent to elevated ICP, venous hypertension can present with many additional nonspecific symptoms, including cognitive decline, dizziness, and malaise, especially when the proximal portion of the SSS is involved. ${ }^{6,7}$ The patient's headaches and other symptoms improved immediately and dramatically after surgery, indicating that apart from the cranial nerve palsy, the vascular malformation was responsible for a majority of the patient's presentation. Overall, the patient had 3 relatively uncommon pathologic processes occurring simultaneously, with 2 , the AVM and temporal arteritis, independently resulting in the patient's primary symptoms of headache and diplopia, respectively. The patient's meningioma was purely incidental and managed with observation.

The present case is notable for several other reasons. First, it depicts an uncommon presentation of a common pathologic process. Temporal arteritis classically presents with headache, jaw claudication, fatigue, malaise, and other constitutional symptoms, as well as the most dreaded symptom of visual loss. Oculomotor nerve palsy is a less common presentation of temporal arteritis, but can rarely be seen in isolation as the main symptom. The underlying pathophysiology is believed to be rooted in vasculitis affecting posterior cerebral artery branches supplying the nerve, ultimately leading to ischemic injury. ${ }^{5}$ Other mechanisms of diplopia related to temporal arteritis include palsies of the fourth and sixth cranial nerves and ischemia of extraocular muscles. ${ }^{8}$ Although visual loss in temporal arteritis is almost always permanent, diplopia typically resolves or improves with steroid therapy, ${ }^{5,8,9}$ as was the case in our patient. Second, the patient's clinical and radiographic course nicely demonstrates the pathophysiology of AVM-associated aneurysms. These aneurysms are typically located along arteries hemodynamically related to the AVM nidus rather than the arterial branch points typically harboring classical berry aneurysms. The high-flow rates through feeding pedicles are believed to drive aneurysm formation and progression, and their presence is believed to be a harbinger of AVM hemorrhage. While AVMassociated aneurysms should be treated if feasible, it is important to recognize the high likelihood of spontaneous regression upon AVM obliteration, especially for distal flow-related aneurysms, in order to avoid unnecessary treatment. ${ }^{3}$ Finally, arteriovenous malformations causing arterialization of the anterior third of the SSS can present with symptoms of global brain dysfunction, and should be considered in the differential diagnosis for dementia. ${ }^{10}$ 


\section{Author contributions}

Dr. Lorenzo Rinaldo: study concept and design, drafting the manuscript, critical revision of the manuscript, approved final manuscript version. Dr. Catherine Arnold Fiebelkorn: study concept and design, drafting the manuscript, critical revision of the manuscript, approved final manuscript version. Dr. John Chen: study concept and design, critical revision of the manuscript, approved final manuscript version. Dr. Giuseppe Lanzino: study concept and design, critical revision of the manuscript, approved final manuscript version.

\section{Study funding}

No targeted funding reported.

\section{Disclosure}

The authors report no disclosures relevant to the manuscript. Go to Neurology.org/N for full disclosures.

\section{References}

1. Silberstein SD. Practice parameter: evidence-based guidelines for migraine headache (an evidence-based review): report of the Quality Standards Subcommittee of the American Academy of Neurology. Neurology 2000;55:754-762.

2. Fang C, Leavitt JA, Hodge DO, Holmes JM, Mohney BG, Chen JJ. Incidence and etiologies of acquired third nerve palsy using a population-based method. JAMA Ophthalmol 2017;135:23-28.

3. Rammos SK, Gardenghi B, Bortolotti C, Cloft HJ, Lanzino G. Aneurysms associated with brain arteriovenous malformations. AJNR Am J Neuroradiol Epub 2016 Jun 23.

4. Larner AJ. False localising signs. J Neurol Neurosurg Psychiatry 2003;74:415-418.

5. Thurtell MJ, Longmuir RA. Third nerve palsy as the initial manifestation of giant cell arteritis. J Neuroophthalmol 2014;34:243-245.

6. Willinsky R, Goyal M, Montanera W. Tortuous, engorged pial veins in intracranial dural arteriovenous fistulas: correlations with presentation, location, and MR findings in 122 patients. Am J Neuroradiol 1999;20:1031-1036.

7. Willinsky R, Terbrugge K, Montanera W, Mikulis D, Wallace MC. Venous congestion: an MR finding in dural arteriovenous malformations with cortical venous drainage. AJNR Am J Neuroradiol 1999;15:1501-1507.

8. Ross M, Bursztyn L, Superstein R, Gans M. Multiple cranial nerve palsies in giant cell arteritis. J Neuroophthalmol 2017;37:398-400.

9. Gaudre N, Michaud M, Soler V, Lozano S, Gaudin C, Balardy L. Giant cell arteritis: a reversible cause of oculomotor nerve palsy. Presse Med 2015;44:859-860.

10. Hurst RW, Bagley LJ, Galetta S, et al. Dementia resulting from dural arteriovenous fistulas: the pathologic findings of venous hypertensive encephalopathy. AJNR Am J Neuroradiol 1998; 19:1267-1273. 


\section{Neurology}

\section{Clinical Reasoning: Headaches and double vision in a 68-year-old woman Lorenzo Rinaldo, Catherine E. Arnold Fiebelkorn, John J. Chen, et al. Neurology 2018;91;e785-e789 \\ DOI 10.1212/WNL.0000000000006046}

This information is current as of August 20, 2018

\section{Updated Information \& Services}

References

Subspecialty Collections

Permissions \& Licensing

Reprints including high resolution figures, can be found at: http://n.neurology.org/content/91/8/e785.full

This article cites 9 articles, 3 of which you can access for free at: http://n.neurology.org/content/91/8/e785.full\#ref-list-1

This article, along with others on similar topics, appears in the following collection(s):

Arteriovenous malformation

http://n.neurology.org/cgi/collection/arteriovenous_malformation Clinical neurology examination

http://n.neurology.org/cgi/collection/clinical_neurology_examination Diplopia (double vision)

http://n.neurology.org/cgi/collection/diplopia_double_vision

Primary brain tumor

http://n.neurology.org/cgi/collection/primary_brain_tumor

Information about reproducing this article in parts (figures,tables) or in its entirety can be found online at:

http://www.neurology.org/about/about_the_journal\#permissions

Information about ordering reprints can be found online:

http://n.neurology.org/subscribers/advertise

Neurology ${ }^{\circledR}$ is the official journal of the American Academy of Neurology. Published continuously since 1951 , it is now a weekly with 48 issues per year. Copyright @ 2018 American Academy of Neurology. All rights reserved. Print ISSN: 0028-3878. Online ISSN: 1526-632X.

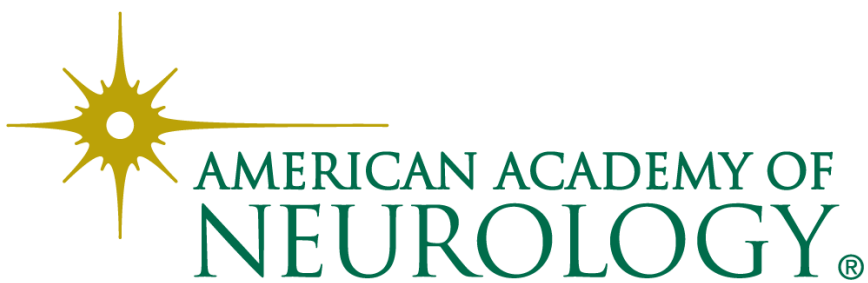

